\title{
Proceeding
}

10th INSHS International Christmas Sport Scientific Conference, 4-5 December 2015. International Network of Sport and Health

Science. Szombathely, Hungary

\section{Measuring of sport specific skills of football players}

\author{
MIKLÓS KOLTAI ${ }^{1 \unlhd}$, DIETMAR WALLNER², ÁDÁM GUSZTAFIK ${ }^{1}$ ZOLTÁN SÁFÁR ${ }^{1}$, HENRIETTE \\ DANCS ${ }^{1}$, HELMUT SIMI², MARCEL HAGENAUER ${ }^{2}$, ANNA MARIA BUCHGRABER ${ }^{2}$ \\ 1 Institute of Sport Science, University of West - Hungary, Hungary \\ ${ }^{2}$ FH-Joanneum, Bad Gleichenberg, Austria
}

\begin{abstract}
The Institute of Sport Science at the University of West-Hungary, and the FH-Joanneum - together with students majoring in sport science - started a collaborative international research aimed at assessing the sport-specific skills of football players. The study closely monitored football players - from leagues at different levels - in terms of choice reaction time, short and long pass skills and agility skills with and without a ball. The most modern device available, the SmartSpeed - a photoelectric stopwatch system - was used for the measurements. The data obtained by the applied internationally standardized tests can be compared in terms of players from leagues at different levels. The study occurred using correlation analysis $(p<0.05)$, and we used linear regression to compare laterality. The hypothesis that teams playing in higher league are significantly more successful in terms of the evaluated technical parameters has not been verified in all cases. There are interesting results regarding the differences between moving to the opposite side with and without ball. The results of the Hungarian team ( $N=97$ players) can be compared to those of the Austrian and international players. Key words: FOOTBALL, SHORT PASS TEST, LOBBED BALL TEST, ZIG ZAG DRIBBLING TEST, SMARTSPEED.
\end{abstract}

\footnotetext{
Corresponding author. University of West - Hungary, Savaria Campus, Institute of Sport Science, Szombathely, Hungary E-mail: koltai.miklos@mnsk.nyme.hu 10th INSHS International Christmas Sport Scientific Conference, 4-5 December 2015. International Network of Sport and Health Science. Szombathely, Hungary. JOURNAL OF HUMAN SPORT \& EXERCISE ISSN 1988-5202

(C) Faculty of Education. University of Alicante doi:10.14198/jhse.2016.11.Proc1.12
} 


\section{INTRODUCTION}

The scientific and technical development of football has been spectacular and significant. Football requires complex motor skills, which are applied alternately during a match. Therefore it is hard to perform a separate analysis of the technical, tactical, physical and mental skills. The complexity of certain tests provides an exact picture of the skills of the football players, from which both players and coaches can draw conclusions.

The current research deals with analyzing technical skills. The applied analytical instruments and methods almost entirely cover the technical skills, both with and without the ball, used by the football players during matches. The analyzed skills are crucial in terms of success. The applied tests provide laboratory conditions for the participants, and, at the same time they appropriately show the individual situations. It must be highlighted that our work forms part of an Austrian-Hungarian international study between two universities, involving students majoring in sport science. In the current paper however, we summarize the Hungarian results.

\section{Literature review}

Experts have long been looking for tests that better model the game situations in order to potentially improve the performance of players. Studying the scientific literature, we focused on the football-specific skills and the tests regarding their physiological effects (Bangsbo and Mohr, 2011). A player has the ball for 53.4 seconds in average during a match (Carling, 2010). Depending on the position of a given player, the average technical tasks during a match are as follows: 50 encounters with the ball, 50 turns, and 30 passes (Stolen and peers, 2005). These solutions come as the result of a series of decisions which have to be made under time pressure, finding the most optimal outcome. According to Williams (1993), it can already be assessed in childhood if an individual has high or low skills at football-specific decision making. The decision is followed by the correct technical execution, which has been examined in several regards for junior (Zago et al, 2016; Forsman et al, 2015) and women players (Pedersen et al, 2014).

Furthermore, changing directions and turning are also essential part of football - offense and defense perform the most of these tasks (Bloomfield and peers, 2007), which can be of importance when creating a differentiated training program. It is important to note that agility and speed are subjective skills in this sport, thus they should be examined separately (Buttifant and peers, 2002). When examining the distance covered during a match, all 4 directions should be considered (Bangsbo and peers, 1997).

\section{Hypotheses}

$\mathrm{H} 1$ : Teams in different levels of leagues perform differently during testing.

$\mathrm{H} 2$ : Teams in higher leagues have significantly better results.

H3: In terms of laterality, we assume that the results of well-trained players are better even with their weaker leg.

\section{MATERIAL AND METHODS}

When selecting the samples, it had to be considered that the results of the two countries should be comparable later. As a result, we included two first league adult teams (one from women's and one from men's division), a third and a forth league team, as well as an U17 and an U15 team ( $\mathrm{N}=97$ players). Measurements occurred using the most modern devices available: SmartSpeed and other photoelectric devices. With the help of these instruments, players, coaches, and experts can obtain information on what specific skills of football players need to be improved. All three tests are internationally standardized, thus 
promoting easy comparison. Further advantage of these tests is that they provide an exact picture of performance.

Short pass test (Fig. 1):

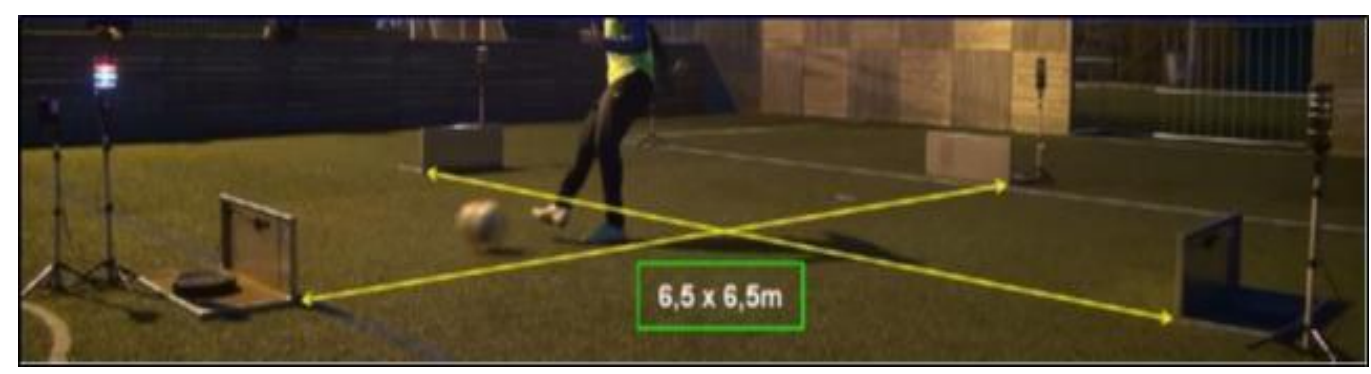

Figure 1. Short pass test

The player stands in the middle of a $6,5 \mathrm{~m}$ by $6,5 \mathrm{~m}$ square and performs 15 passes to flashing lights displayed on a wall. The device registers the time; in case of a bad pass, the player can continue the test, however, after three wrong passes, the test becomes invalid. The player has two attempts and the better result gets registered. Alongside the short pass skills, the test examines choice reaction time, and spatial perception.

Required equipment: 4 pass walls, 4 optical goals, 1 SmartScore stopwatch, 5 telescopic tripods and a control unit (the SmartSpeed devices), 410 kilogram weight plates, 1 football, 1 measuring tape.

Lobbed ball test (Fig. 2):

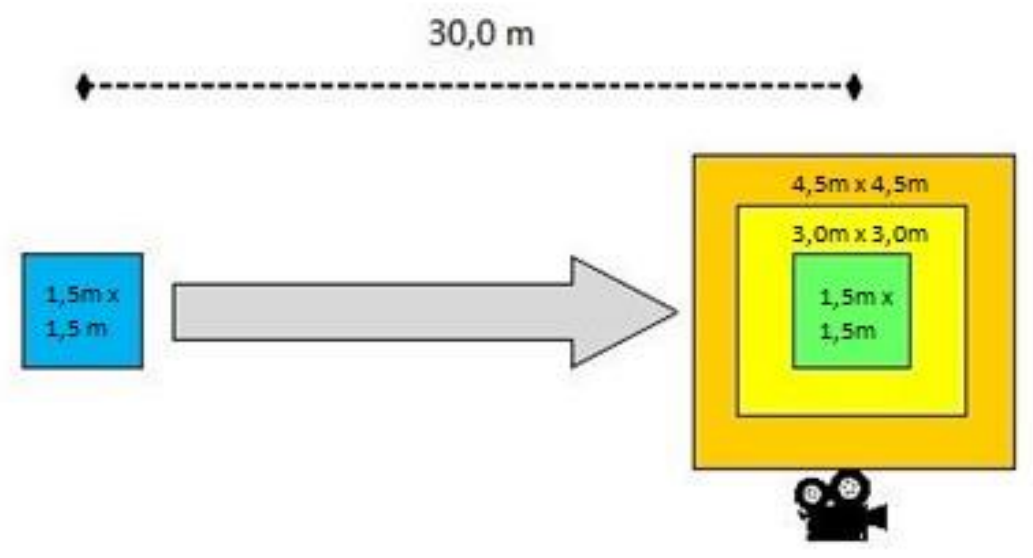

Figure 2. Lobbed ball test

The player has to lob pass the ball - which can either be still, or the player may send it rolling - to any of the squares situated 30 meters from the square they are standing in. Another player standing in the middle of the smallest square receives the pass. 
When this player receives the lobbed pass in any of the three squares, the other player scores. If the ball lands in the smallest, inner square, the player gets 3 points; if it lands in the $3 \mathrm{~m}$ by $3 \mathrm{~m}$ square, then 2 ; while the outer square is worth 1 point. The player has 5 attempts with each leg.

Scores are based on the square the ball is received in.

Required equipment: 16 small buoys, 1 measuring tape, 1 football, 1 video camera with tripod.

Zig zag dribbling test (Fig. 3):

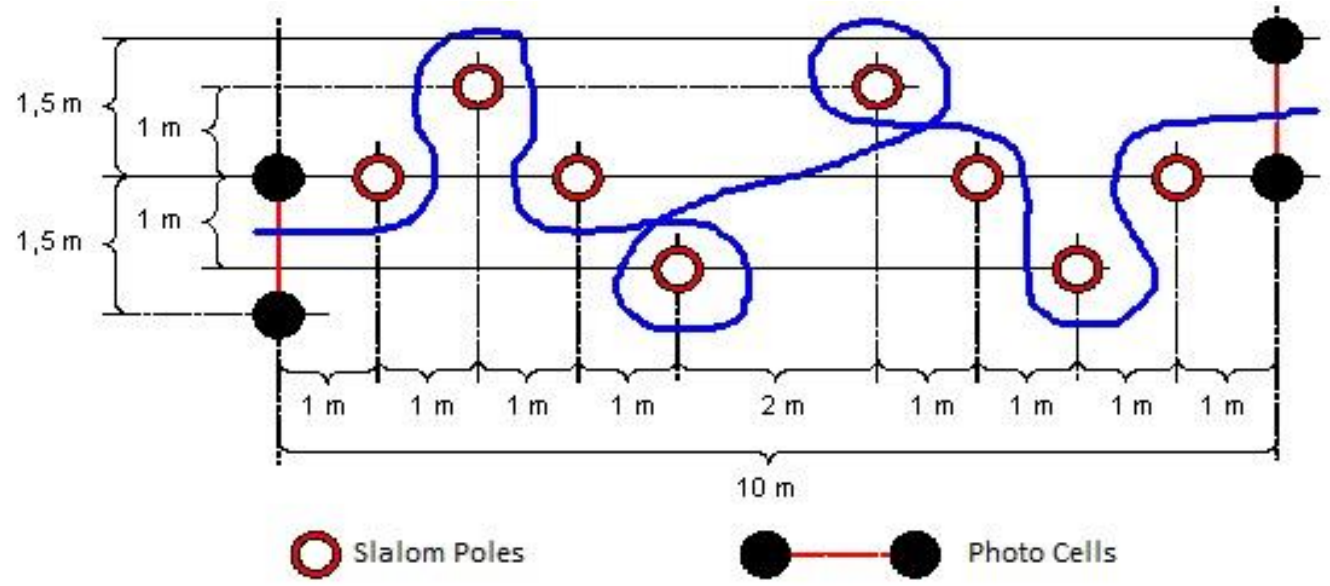

Figure 3. Zig zag dribbling test

The testing ground is set up as can be seen in the appendices. The test requires the players to perform the fastest and most perfect execution - first without the ball, then dribbling with each leg. If the player fails during the slalom dribbling, they can try again once.

Required equipment: 1 timekeeping light gate, 8 posts with $2 \mathrm{~kg}$ base

The data was processed using the GraphPad Prism program focusing on average, standard deviation, linear regression and correlation matrix analysis.

\section{RESULTS}

Once the data was sorted, we applied linear regression to examine homogeneity within the team. As seen on the figure, standard deviation is smaller for those teams where the function shows the low steepness. Steady, good performance within the team is key to success.

Short pass test (Fig. 4): The test measuring the most complex skills. 

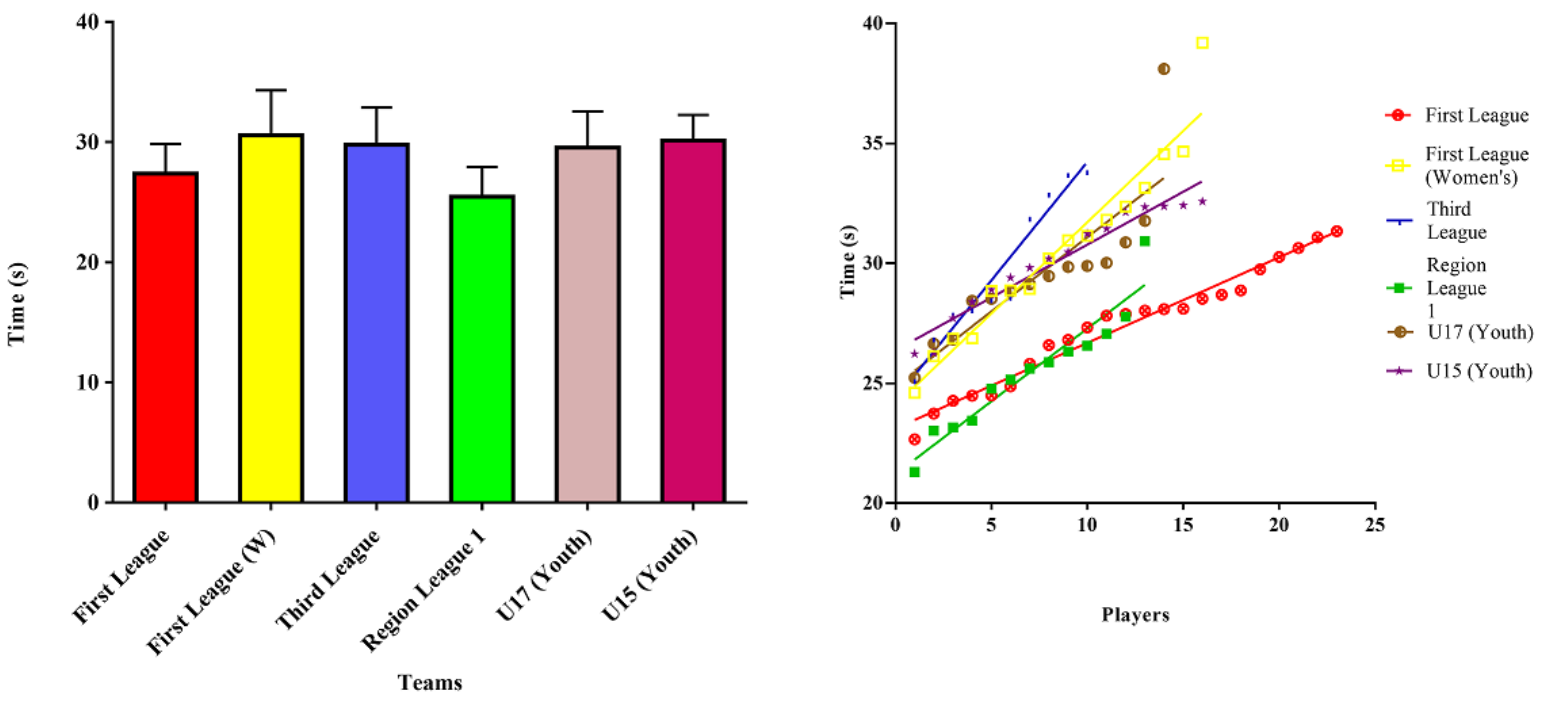

Figure 4. Average results (left side), linear regression (right side) - Short pass test

Smaller the time results in the figure, better the score. In terms of results, the first league team was followed by the region league 1 team. The best result was 21.3 seconds.

It is apparent that there are no big differences between the two junior teams, however, the experienced players reached better results which can be explained with more comprehensive spatial perception and higher technical level.

Lobbed ball test (Fig. 5):
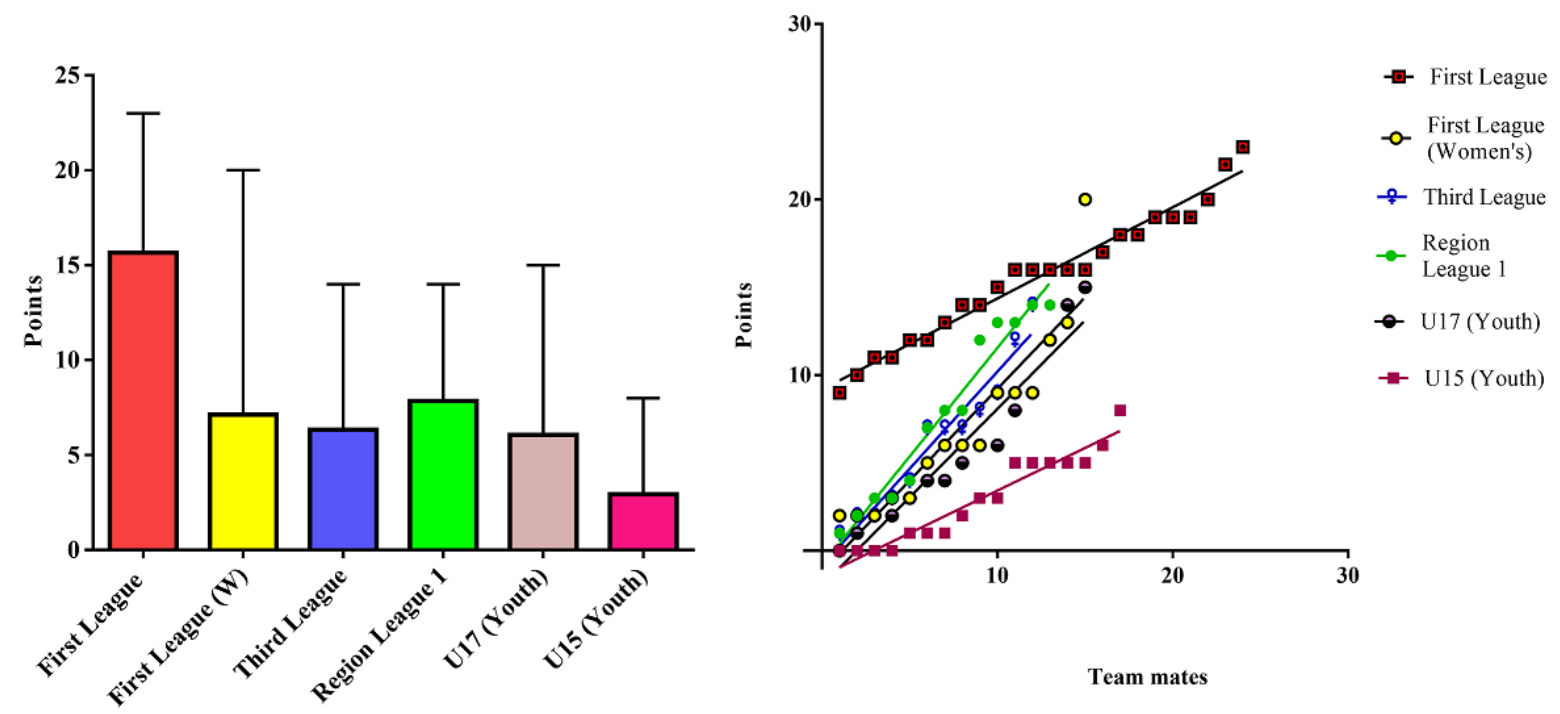

Teams 
Figure 5. Averages (left side), linear regression (right side) - Lobbed ball test

The figure shows the average lobbed pass results of the 6 teams. The closer the standard deviation within the team, the more similarly skilled players it has. The first league team is outstanding based on both the minimum and maximum scores. This is supported by the fact that there is a high number of players with the same score. Although the U15 team has less points, the standard deviation within the team is small.

Zig zag dribbling test (Fig. 6):
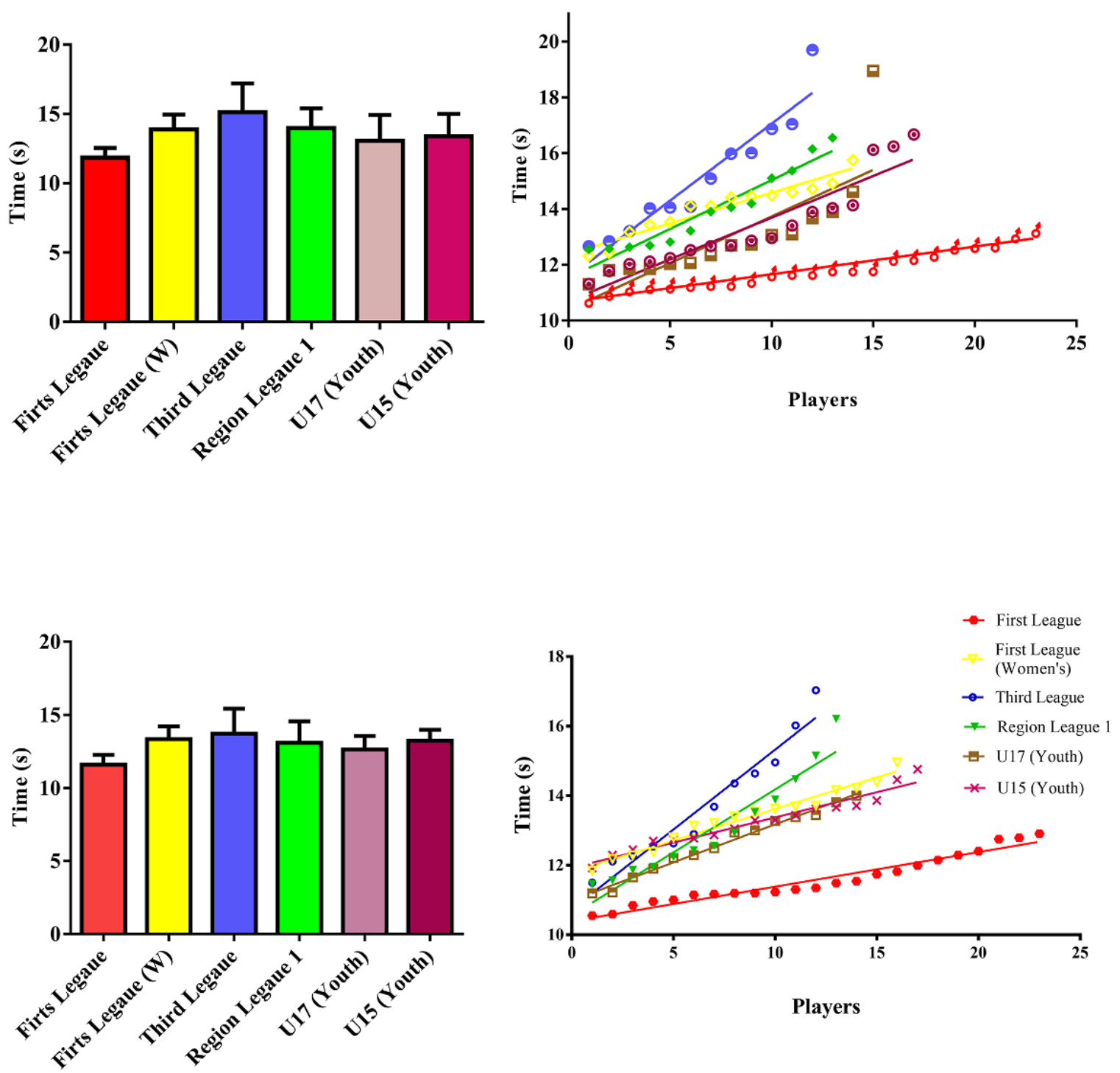

Figure 6. Averages and linear regression left and right leg - Zig zag dribbling test

In terms of laterality, we examined dribbling with both the dominant and the weaker leg. The two-footed players have an advantage during dribbling as the variations of decisions multiply. The results we found show 
an intriguing picture. Based on our linear regression analysis, it can be noted that the first league team excel, while looking at the 5 other teams there are no notable differences in terms of laterality. The results of the junior teams are not lower compared to the other teams.

\section{Correlation matrix analysis:}

Correlation matrix analysis was aimed at finding the relations between the measured parameters. We found strong correlation values for each team, although with regards to the technical skills only.

The region league 1 team was one of most striking ones in terms of the relation between slalom dribbling with right leg and short pass ( $r=0.67)$, while the first league $(W)$ team showed strong correlation between dribbling with left leg and giving lobbed pass $(r=0.71)$.

Altogether, the first class team gave the steadiest performance in all three tests.

As seen in the figure, the standard deviation from the data set shows a much clustered picture, meaning that skill levels are on a similar between the players. Except for the short pass test, the other ones show low steepness which indicates good technical skills.

\section{Laterality analysis}

Our last hypothesis examines laterality. We could perform two tests (long pass test and dribbling test) separately for both left, and right leg. Higher the score in the long pass test, better the rank, while in the dribbling test the lower score means better result.

One of our objectives during the analysis was to look at which leg was better at passing, and then whether or not that leg was more skilled at dribbling too. Furthermore, we examined if a player was more skilled than the others with one particular leg, then whether or not they were also better with their other leg (Fig. 7).

Table 1. Combined correlation matrix for laterality analysis

\begin{tabular}{lrrrr}
\hline & Dribbling right leg & Dribbling left leg & Lobbed right leg & Lobbed left leg \\
\hline Dribbling right leg & & 0.511 & -0.382 & -0.325 \\
Dribbling left leg & 0.511 & & -0.212 & -0.516 \\
Lobbed right leg & -0.382 & -0.212 & & 0.501 \\
Lobbed left leg & -0.325 & -0.516 & 0.501 & \\
\hline
\end{tabular}




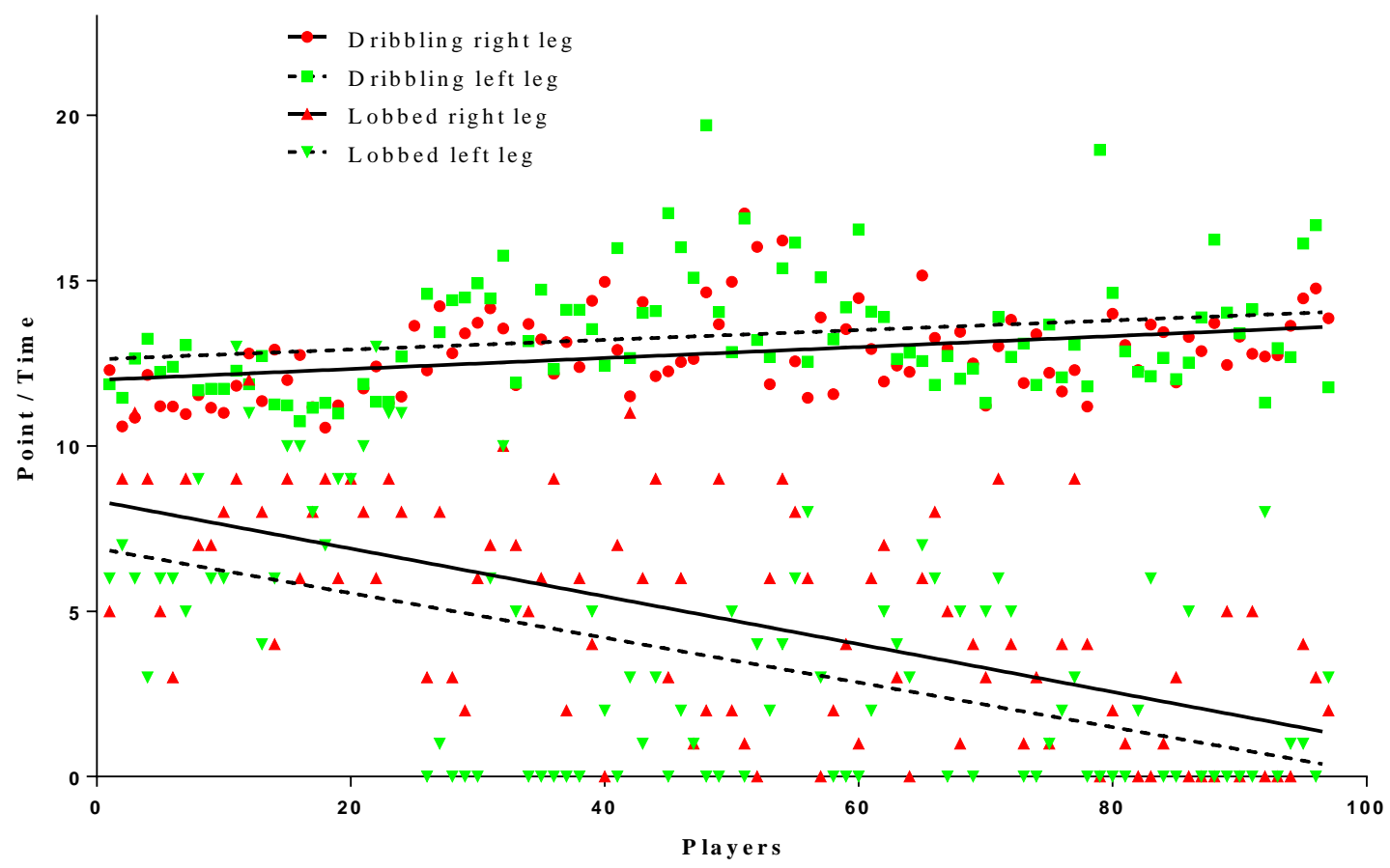

Figure 7. Laterality analysis with linear regression

The results indicate the most of the players are right-footed. This is also supported by the fact that the 'red' regression lines are surrounded by the 'green' ones. Right-footedness is indicated by the 'green-red-redgreen' movement upwards from below (i.e. the $X$ axis value), whereas 'red-green-green-red' implies leftfootedness. If there is no such color order and the colors are shuffled, we can state that there is no distinctive dominant leg.

When the teams are arranged in order (linear regression), we can see the trend that the performance of the players worsen as we look at teams from lower leagues (the order of the players within a given team is random).

Assessing the performance of two-footed players is subjective. We considered two-footed those players, whose results showed only 2 points difference between the legs in the long pass test, and maximum of 1 second in the dribbling test. These players are marked with black color in the function. This skill can be observed for $27 \%$ of all the players; on a team level, we can see the following:

first league: $45.8 \%$ (11 players),

first league (W): $25 \%$ (4 players),

third league: $8.3 \%$ (1 player),

region league $1: 7.7 \%$ (1 player),

U17: $20 \%$ (3 players),

U15: $35.3 \%$ (6 players).

The high percentage indicates a steady good performance in terms of the more qualified teams, while it suggests imperfect execution by the players of the junior teams. 
As shown by the combined correlation matrix, with regards to dribbling and passing there is a $r=0.5$ correlation between the legs. This means that if a player is better than another player at these tasks using one particular leg, then he/she should also be more skilled with the other leg, therefore most of the players have a dominant lateral.

Based on the negative correlation between dribbling and passing ( 1 st line) it can be concluded that the players who are better at dribbling with right leg, are also better at passing with right leg than with the left one. However this is not a notable difference compared to the striking distinctions seen in the case of using the left leg (2nd line).

\section{Hypotheses Verification}

The first of our hypotheses has been verified as the teams of different leagues, gender, and age produced diverse results, as shown by the average results.

The second hypothesis, that teams in higher leagues produce significantly better result, has not been verified. This interesting finding has several explanations, e.g., lower league teams have many experienced players who played in higher leagues previously - therefore they outscore the rest of the players in the league in terms of technical skills.

The third hypothesis has partly been verified: although the results of the first league team show that most players are also significantly better with their non-dominant leg, it has not been confirmed for all experienced players.

\section{CONCLUSIONS}

The players and the coaches were motivated by the tests, which resulted in a competition between players. They enjoyed the tests; they were enthusiastic and provided their best effort. The coaches gave positive feedback that they found the tests extremely beneficial.

The measured data can directly help the coaches in their jobs. The analysis of the results provides opportunities for differentiated development of skills. The better results the teams get in these tests, the more successful they become during matches. The technical execution applied in the tests can manifest in the game style of the teams since these solutions occur in every game situation.

Our goal is to have 50 samples per league so that we could better see the statistical characteristics which provide a detailed picture of technical skills of Hungarian teams. We performed some experimental testing with women and junior teams as well to open up new prospects which can serve as grounds for future research.

We are enthusiastic to continue the cooperation with our Austrian partner, and to share useful practical experience with the university students.

\section{REFERENCES}

1. Stolen T., Chamari K., Castagna C., Wisloff U., (2005): Physiology of Soccer. Sports Medicine. 35(6), 501-536. 
2. Carling, Chris (2010): Analysis of Physical Activity Profiles When Running with the Ball in a Professional Soccer Team. Journal of Sports Sciences 38 (3), 319 - 326

3. Buttifant D., Graham K., Cross K. (2002): Agility and speed in soccer players are two different performance parameters. In: Science and football IV. Eds: Spinks W., Reilly T., Murphy A., editors. London, Routledge; 329-332

4. Bloomfield, J.,Polman R., O'Donoghue, P., (2007): Physical Demands of Different Positions in FA Premier League Soccer. J Sports Sci Medicine, 6 (1), 63-70.

5. Bangsbo J. (1997): The physiology of intermittent activity in football. In: Science and Football III. Eds: Reilly T., Bangsbo J., Hughes M., editors. London, E \& FN Spon. 43-53.

6. Bangsbo J., Mohr, M. (2012): Fitness Testing in Football. Bangsbosport.

7. Zago M., Piovan A.G., Annoni I., Ciprandi D., laia F.M., Sforza C. (2016): Dribbling determinants in sub-elite youth soccer players. Journal of Sport Sciences, 34 (5), 411-9.

8. Forsman H., Grastén A., Blomqvist M., Davids K., Liukkonen J., Konttinen N. (2015): Development of perceived competence, tactical skills, motivation, technical skills, and speed and agility in young soccer players. Journal of Sport Sciences, 28, 1-8.

9. Pedersen AV., Loras H., Norvang OP., Asplund J., (2014): Measuring soccer technique with easy to - administer field tasks in female soccer players from four different competitive levels. Perceptual and Motor Skills, 119(3), 961-970.

10. http://www.gosportstech.com/smartspeed.php (last viewing: 21.01.2016.)

11. http://www.fusionsport.com/products/smartspeed-timing-gates-system (last viewing: 21.01.2016.). 